\title{
ГЕНДЕРНЫЕ ОСОБЕННОСТИ АДАПТАЦИИ СУБЪЕКТОВ К СИТУАЦИИ СМЕНЫ ВИДОВ ПРОФЕССИОНАЛЬНОЙ ДЕЯТЕЛЬНОСТИ
}

Исслед.выполнено при финансовой поддержке Российского фонда фундаментальных исследований, проект №19-013-00308 Фомина Е.А., Соломонов В.А. (ФГБОУ ВО «Северо-Кавказский федеральный университет", Ставрополь, Россия) fea30@mail.ru,vlads67@mail.ru 乙tipluјшgर्ume uर्u. 31.07.2021

9pupunuर्ume uर्u. 26.08.2021

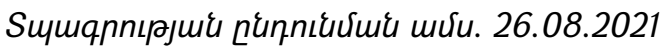

Рассмотрены особенности адаптации субъектов к ситуации смены видов профессиональной деятельности с учетом их гендерной принадлежности. В исследовании приняли участие 292 человека, из них 146 мужчин, 146 женщин, в том или ином виде осуществляющих смену видов профессиональной деятельности (проходящих обучение по различным программам, безработных, занятых поиском новой вакансии). Эмпирический материал собран с помощью компьютерного тестирования, использованы стандартизированные психологические методики. У мужчин установлены связи между всеми компонентами адаптивности, жизнестойкости и копинг-стратегиями; ключевым предиктором является «вовлеченность». Для мужчин когнитивные копинг-стратегии не являются продуктивными. У респондентов женской выборки не выявлены значимые корреляционные связи между «моральной нормативностью» как фактором адаптивности, компонентами жизнестойкости и копинг-стратегиями, ключевым фрактором выступает «принятие риска». Женщины склонны использовать когнитивные и эмоциональные копинг-стратегии.

Выявлено, что способность адаптироваться к ситуации смены видов профессиональной деятельности у всех субъектов связана с готовностью к принятию перемен в жизни («адаптивные способности»); со стремлением включиться в деятельность, от которой можно получать удовольствие («вовлеченность»); с открытостью новому опыту («принятие риска»).

Ключевые слова: профессиональная деятельность, жизнестойкость, адаптация, копинг-стратегии, гендерные особенности.

DOI: https://doi.org/10.46991/SBMP/2021.4.2.159

Ситуация смены видов профессиональной деятельности в ходе профессионализации субъекта становится все более привычной в современном VUCA- 
мире. Причины могут быть связаны как с объективными событиями (прекращение деятельности организации, изменение функционала по должности и т.п.), так и с обстоятельствами субъективного плана (желание заниматься чемлюбо другим, необходимость совмещать трудовые и семейные роли и т.п.).

Во всех подобных случаях субъект оказывается в условиях, в которых возрастает уровень стрессовых нагрузок самого разного плана, к которым он вынужден адаптироваться, и в конечном счете успешно преодолевать [1]. Во многих случаях изменение профессиональной деятельности связано с необходимостью получить профессиональное обучение или переподготовку, с изменениями карьерной траектории, что особо отмечается исследователями гендерных аспектов феномена карьеры [2].

В данной работе предпринята попытка исследовать особенности адаптации субъектов, находящихся в ситуации смены видов профессиональной деятельности, в зависимости от их гендерной принадлежности.

Цель исследования - выявление предикторов адаптационного потенциала субъектов, находящихся в ситуации смены видов профессиональной деятельности с учетом их гендерной принадлежности.

Методы исследования. В исследовании приняли участие 292 человека, из них 146 мужчин, 146 женщин, проходящих обучение по различным программам, безработных, занятых поиском интересной вакансии, т.е. в том или ином виде осуществляющих смену видов профессиональной деятельности.

Эмпирический материал собран с помощью компьютеризированного тестирования на основе использования стандартизированных тестовых методик.

В состав пакета методик вошли: Тест жизнестойкости, адаптация теста Мадди С., выполненная Леонтьевым Д.А., Рассказовой Е.И. (ТЖ) [3]; Многоуровневый личностный опросник «Адаптивность» Маклакова А.Г., Чермянина С.В. (МЛО-АМ) [4]; Методика диагностики копинг-стратегий Неim Е. (E. Heim) [6].

Статистическая обработка результатов была проведена с помощью программы MS Excel 2016, статистического пакета IBM SPSS Statistics версия 25.0 и IBM SPSS AMOS версия 25. Использовались процедуры описательной статистики, корреляционный анализ, множественный регрессионный анализ методом пошагового исключения переменных в вычислениях, а также моделирование структурными уравнениями. Погрешности измерений обозначены на рисунках, как «е», ошибки модели. Значимые результаты достоверны на уровне $\mathrm{p} \geq 0,05$ по критерию Манна - Уитни.

Результаты исследований. В качестве независимых переменных были выбраны показатели, характеризующие копинг-стратегии и проявления 
жизнестойкости, зависимые переменные - различные компоненты адаптивности человека.

На рисунке 1 представлена структурно-логическая модель адаптивности субъектов в ситуации смены видов профессиональной деятельности для мужской выборки. Ключевым предиктором адаптивности является «вовлеченность» человека, все показатели взаимосвязаны с ней, все положительно. Второй по значению предиктор - «принятие риска», с ним взаимосвязаны «адаптационные способности», «нервно-психическая устойчивость», «коммуникативные особенности.

$\mathrm{X}^{2} / \mathrm{df}=1,433 ; p=00000 ; \mathrm{CFI}=0,999 ; \mathrm{RMSEA}=0,000$

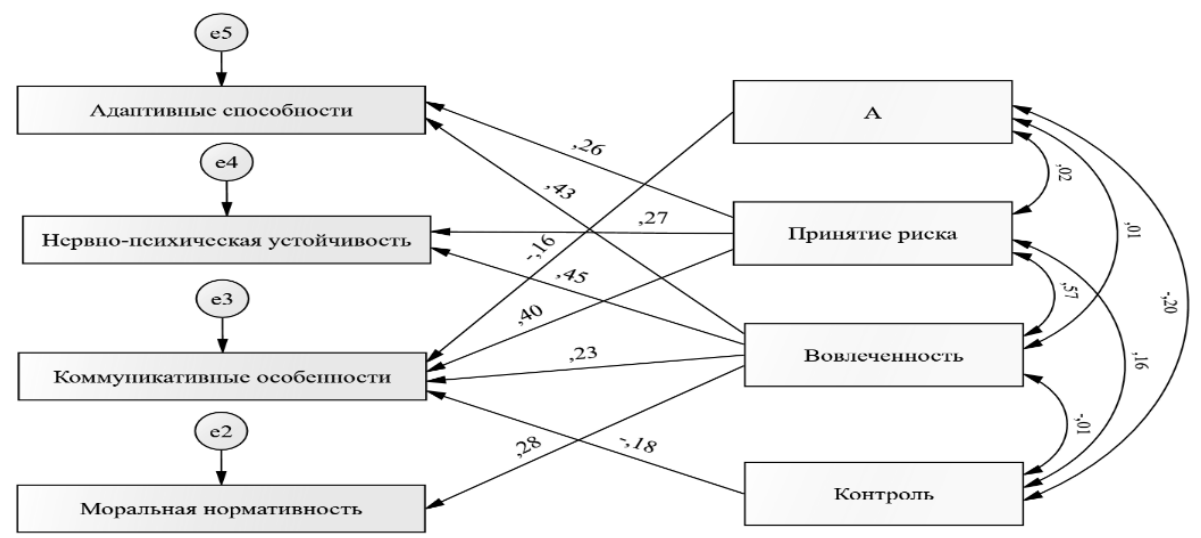

Рисунок 1. Структурно-логическая модель адаптивности субъектов в ситуации смены видов профессиональной деятельности. Мужская выборка

Коммуникативные особенности мужчин в числе предикторов имеют также «когнитивную копинг-стратегию А» $(-0,16)$ и «контроль» $(-0,18)$, причем эти связи отрицательны. Моральная нормативность положительно взаимосвязана только с «вовлеченностью» $(0,28)$.

Для женской выборки результаты изучения предикторов адаптивности ожидаемо отличаются. Данные расчетов представлены на рисунке 2. 


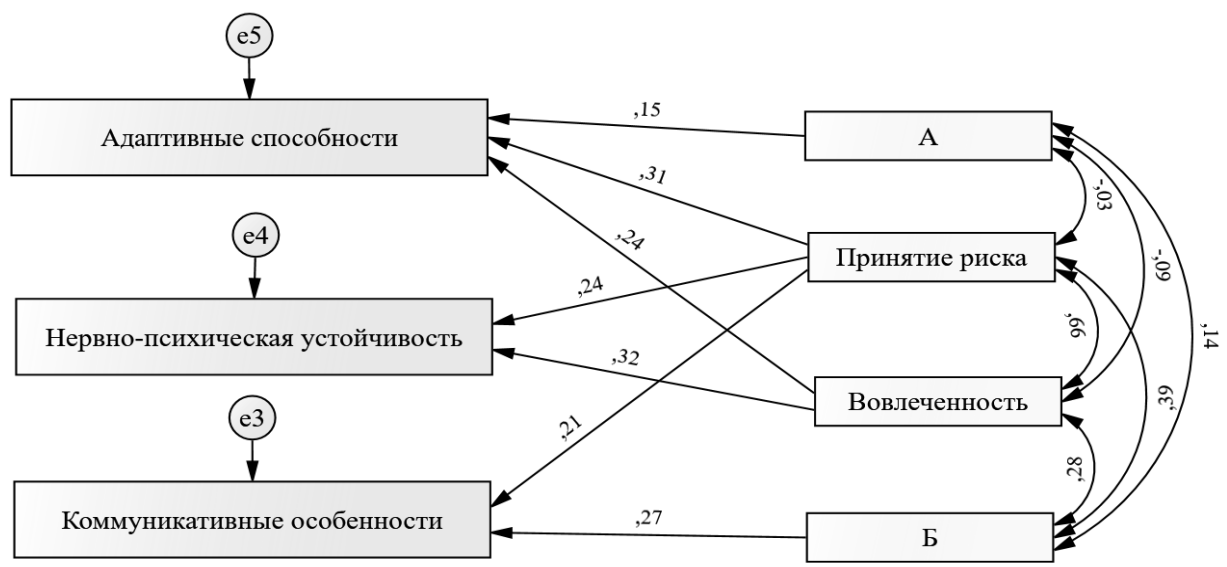

Рисунок 2. Структурно-логическая модель адаптивности субъектов в ситуации смены видов профессиональной деятельности. Женская выборка

Все значимые корреляции между копинг-стратегиями, компонентами жизнестойкости и адаптивности у респондентов из женской выборки положительны.

Ключевым предиктором здесь является «принятие риска», обусловливающее динамику «адаптивных способностей», «нервно-психической устойчивости» и "коммуникативных особенностей». Фактор "вовлеченности» имеет значимое влияние на проявление «адаптивных способностей» $(0,24)$ и «нервнопсихической устойчивости" $(0,32)$. К числу предикторов «коммуникативных особенностей» помимо «принятия риска» $(0,21)$ относятся и «эмоциональные копинг стратегии Б» $(0,27)$. Значимые взаимосвязи между копинг-стратегиями, компонентами жизнестойкости и «моральной нормативностью» у респондентов из женской выборки не выявлены.

По сравнению с данными мужской выборки, результаты респондентовженщин характеризуются однонаправленностью динамики, относительно меньшим количеством взаимосвязей между компонентами модели и меньшей интенсивностью взаимосвязей.

Выводы. Способность адаптироваться к ситуации смены видов профессиональной деятельности, независимо от гендерной принадлежности субъектов, связана с готовностью к принятию перемен в жизни; со стремлением включиться в деятельность, от которой они будут получать удовольствие; с открытостью новому опыту при отсутствии гарантий успеха.

У мужчин в большей степени проявляется вовлеченность в происходящее, они стремятся быть в курсе событий, получать больше информации, связывают перемены в деятельности с возможностью найти нечто стоящее и интересное для себя, хотя и отдают себе отчет в отсутствии гарантий успеха. Адекватность их самооценки и реальное восприятие действительности поддерживается в данной 
ситуации вовлеченностью в процесс, готовностью действовать на свой страх и риск, извлекая новый жизненный опыт из сложившейся ситуации. При этом респонденты сознают, что не все зависит только от них. Это побуждает мужчин к более высокой коммуникативной активности, расширению круга общения и снижению конфликтности. Таким образом, они используют возможность получить полезную информацию о трудоустройстве и поддержку в непростой ситуации. Мужчины не склонны придавать особый смысл происходящим в жизни в данный момент переменам, «отвергают» использование когнитивных копинг-стратегий. Для них важно следовать общепринятым нормам, образу мужчины, что побуждает к активному поиску себя в профессии или на рынке труда.

Адаптируясь к ситуации изменений в профессиональной деятельности, женщины также, как и мужчины, вовлекаются в процесс, готовы развиваться, действовать при отсутствии гарантий успеха. Женщины более склонны преодолевать ситуацию, придавая некий смысл происходящим в их жизни переменам; данный вывод подтверждает ранее полученные данные [5]. Это позволяет им поддержать самооценку и реальное восприятие действительности, самостоятельно регулировать поведение в новой профессиональной ситуации. Повышение коммуникативной активности женщин объясняется их вовлеченностью в происходящие процессы. Общаясь, они получают необходимую информацию, новые впечатления и поддержку. Женщины склонны прибегать к эмоциональным копинг-стратегиям. В целом адаптивное поведение женщин можно охарактеризовать как менее предсказуемое, менее определенное, более индивидуализированное.

В ситуации смены видов профессиональной деятельности, все субъекты вне зависимости от каких-либо объединяющих признаков характеризуются высокой эмоциональностью, вовлеченностью в профессиональную ситуацию, что уже было отмечено нами в докладе на Научной конференции «Психология саморегуляции в контексте актуальных задач образования (к 90-летию со дня рождения акад. РАО О.А. Конопкина)» (Москва, 2021 г.). Гендерная специфика адаптации к смене видов профессиональной деятельности проявляется в выборе или отказе от когнитивных копинг-стратегий, широте жизнестойких убеждений, ориентации на социальные нормы.

\section{Литература}

1. Банщикова Т.Н., Соколовский М.Л. Осознанная саморегуляция как предиктор жизнестойкости субъекта в ситуации смены вида профессиональной деятельности: гендерный аспект // Вестник СевероКавказского фредерального университета. 2021. №1, с.163-170.

2. Гаспарович Е.О, Коваленко Т.К., Токарев А.Г. Гендерные особенности профессиональной мотивациии карьерных ориентаций на разных 
этапах профессионального пути // Управление персоналом и интеллектуальными ресурсами в России. 2018. Т.7. № 3, с. 23-28.

3. Леонтьев Д.А., Рассказова Е.И. Тест жизнестойкости. - М., Смысл, 2006, 63 с.

4. Маклаков А.Г., Чермянин С.В. Многоуровневый личностный опросник «Адаптивность» (МЛО-АМ)/Практическая психодиагностика. Методики и тесты. Учебное пособие. Ред. и сост. Райгородский Д.Я. - Самара, 2001, с. 549-558.

5. Соломонов В.А. Саморегуляция и ценностные ориентации субъекта на этапе освоения нового вида профессиональной деятельности: гендерная специфика // Интеграция педагогической науки и практики в современных условиях: сб. научных трудов / под ред. Шаповалова В. К., Игропуло И. Ф., Ставрополь: изд-во СКФУ, 2020. - 204 с, с. 29-34.

6. Heim E. Coping und Adaptivitat: Gibt es geeignetes oder ungeeignetes Coping // Psychother., Psychosom., med. Psychol. 1988, № 1, pp. 8-17.

\section{GENDER FEATURES OF ADAPTATION OF SUBJECTS TO THE SITUATION OF CHANGE OF TYPES OF PROFESSIONAL ACTIVITIES}

Fomina E.A., Solomonov V.A. (North-Caucasus Federal University, Stavropol, Russia)

The features of adaptation of subjects to the situation of changing types of professional activity, taking into account their gender, are considered. The study involved 292 people, including 146 men, 146 women, who in one form or another change their professional activities (undergoing training in various programs, unemployed, looking for a new vacancy). Empirical material was collected using computer testing, standardized psychological methods were used. In men, connections have been established between all components of adaptability, resilience and coping strategies; the key predictor is "engagement". For men, cognitive coping strategies are not productive. The respondents from the female sample did not reveal significant correlations between "moral normativity" as a factor of adaptability, components of resilience and coping strategies, the key factor being "risk taking". Women tend to use cognitive and emotional coping strategies. It was revealed that the ability to adapt to the situation of changing types of professional activity in all subjects is associated with the readiness to accept changes in life ("adaptive abilities"); with the desire to get involved in activities that you can enjoy ("involvement"); with an openness to new experience ("risk taking").

Keywords: professional activity, hardines, adaptation, coping strategies, gender characteristics. 